\title{
Metallurgy and Ceramics/Superplasticity in Metals and Ceramics
}

T. G. Nieh

February 6, 2002

U.S. Department of Energy

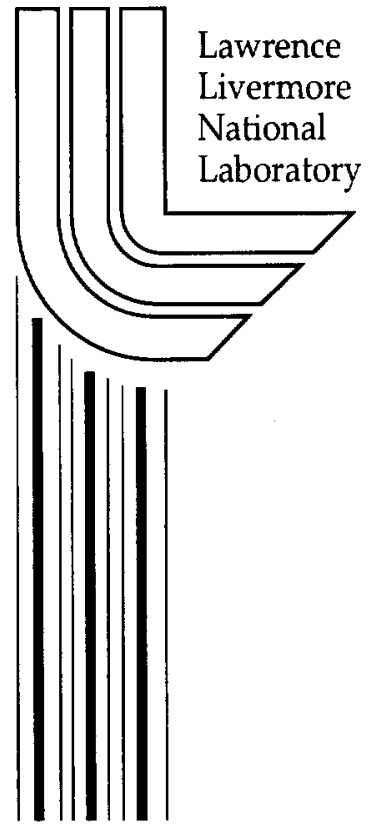




\section{DISCLAIMER}

This document was prepared as an account of work sponsored by an agency of the United States Government. Neither the United States Government nor the University of California nor any of their employees, makes any warranty, express or implied, or assumes any legal liability or responsibility for the accuracy, completeness, or usefulness of any information, apparatus, product, or process disclosed, or represents that its use would not infringe privately owned rights. Reference herein to any specific commercial product, process, or service by trade name, trademark, manufacturer, or otherwise, does not necessarily constitute or imply its endorsement, recommendation, or favoring by the United States Government or the University of California. The views and opinions of authors expressed herein do not necessarily state or reflect those of the United States Government or the University of California, and shall not be used for advertising or product endorsement purposes.

This work was performed under the auspices of the U. S. Department of Energy by the University of California, Lawrence Livermore National Laboratory under Contract No. W-7405-Eng-48.

This report has been reproduced directly from the best available copy.

Available electronically at http://www.doc.gov/bridge

Available for a processing fee to U.S. Department of Energy

And its contractors in paper from

U.S. Department of Energy

Office of Scientific and Technical Information

P.O. Box 62

Oak Ridge, TN 37831-0062

Telephone: (865) 576-8401

Facsimile: (865) 576-5728

E-mail: reports@adonis.osti.gov

Available for the sale to the public from

U.S. Department of Commerce

National Technical Information Service

5285 Port Royal Road

Springfield, VA 22161

Telephone: (800) 553-6847

Facsimile: (703) 605-6900

E-mail: orders@ntis.fedworld.gov

Online ordering: http://www.ntis.gov/ordering.htm

\section{OR}

Lawrence Livermore National Laboratory

Technical Information Department's Digital Library

http://www.llnl.gov/tid/Library.html 


\title{
Metallurgy and Ceramics/Superplasticity in Metals and Ceramics
}

\author{
Principle Investigator: T. G. Nieh
}

\section{Summary of accomplishments}

In the past three years, we have carried out a number of studies on the deformation and superplasticity of fine-structured materials. The goal was to develop an understanding on the deformation-microstructure relationship in these advanced materials and to improve further their properties through microstructural control. In the following, we describe only some of the key results and observations from these studies.

\section{Superplasticity of Al-Mg based alloys (Relevant publications are listed in Appendix P1)}

Al-Mg based alloy is one of the most cost-effective structural aluminum alloys used for lightweight vehicles. As a result, significant efforts have been made to improve the forming, and particularly superplastic forming of AlMg alloys. To understand the superplastic deformation, we carried out a systematic study with these alloys alloyed with different amounts of $\mathrm{Mn}$ and $\mathrm{Zr}$, and different grain sizes. In the case of binary $\mathrm{Al} \mathrm{Mg}$ alloy, we found that, under conditions for which solute-drag creep controls deformation in AtMg alloys, grain size in the range of 30 to $450 \mu \mathrm{m}$ affects neither strain-rate sensitivity nor flow stress at a given creep rate. A large grain size has a slightly adverse effect on tensile ductility during solute-drag creep due to the resulting roughness of the specimen surface. Under conditions of solute-drag creep, an increase in $\mathrm{Mg}$ concentration for $\mathrm{Al} \mathrm{Mg}$, within the 2.8-5.5 wt.\% range, increases strain-rate sensitivity only slightly from $m=0.29$ to $m=0.32$. Consistent with the mechanics predictions, this difference does not have a significant influence on the failure strain. A strain-rate sensitivity of $m=0.3$, which occurs during solute-drag creep, is sufficient to provide tensile ductility on the order of $300 \%$ when failure occurs by necking. Tensile ductilities of $250 \%$ can be consistently achieved in coarse-grained, binary alloys by means of the high strain-rate sensitivity provided by solute-drag creep.

Dilute ternary additions of $\mathrm{Mn}$ and $\mathrm{Zr}$ to $\mathrm{Al}-3.0 \mathrm{Mg}$, at or near the limits of solubility, decrease ductility and slightly decrease strain-rate sensitivity. Ternary $\mathrm{Mn}$ additions of $0.46 \mathrm{wt} . \%$ and higher greatly decrease ductility. Ternary additions of $\mathrm{Mn}$ above the solubility limit in $\mathrm{AHMg}$ alters the failure mechanism from necking controlled to cavitation controlled, primarily because of an increase in second-phase particles. A temary addition of $0.18 \mathrm{wt} \% \mathrm{Zr}$ to $\mathrm{Al} 3.0 \mathrm{Mg}$ results in extensive cavitation for 
temperature and strain-rate conditions under which solute-drag creep occurs. TEM study of the alloy revealed only a few intra-granular particles of approximately $20 \sim \mathrm{nm}$ in diameter and non-homogeneously distributed in the matrix.

Due to the ineffectiveness of $\mathrm{Zr}$ to refine grain size in $\mathrm{Al} \mathrm{Mg}$, Sc was subsequently added. Scandium is the only alloying element to form an equilibrated, thermally-stable, coherent $\mathrm{L}_{2} 2$ phase, i.e. $\mathrm{Al}_{3} \mathrm{Sc}$, in aluminum. The lattice mismatch between $\mathrm{Al}_{3} \mathrm{Sc}$ and $\mathrm{Al}$ is only about $1.4 \%$. As a result, the $\mathrm{Al}_{3} \mathrm{Sc}$ precipitate is unusually resistant to coarsening, and extremely effective in stabilizing substructure and preventing grain growth in aluminum alloys. We carried out a study with a cold-rolled $\mathrm{Al}-6 \mathrm{Mg}-0.3 \mathrm{Sc}$ alloy at temperatures between 450 and $560^{\circ} \mathrm{C}$ and strain rates between $10^{-4}$ and $10^{0} \mathrm{~s}^{-1}$. We found that the alloy exhibited superplasticity at relatively high strain rates $\left(\sim 10^{-2} \mathrm{~s}\right.$ 1). At a strain rate of $10^{-2} \mathrm{~s}^{-1}$ there exists a wide temperature range $\left(475-520^{\circ} \mathrm{C}\right)$ within which the tensile elongation is extraordinarily large (over $1000 \%$ ). There also exists a wide strain rate range $\left(10^{-3}-10^{-1} \mathrm{~s}^{-1}\right)$ within which the tensile elongation is over $500 \%$. As expected, the presence of $\mathrm{Sc}$ in the alloy results in a uniform distribution of fine coherent $\mathrm{Al}_{3} \mathrm{Sc}$ precipitates which effectively pin grain and subgrain boundaries during static and continuous recrystallization. As a result, the alloy retains its fine grain size $(\sim 7 \mu \mathrm{m})$, even after extensive superplastic deformation $(>1000 \%)$. During deformation, dislocations with a high Schmidt factor slip across subgrains but are trapped by subgrain boundaries, as a result of the strong pinning of $\mathrm{AbSc}_{3} \mathrm{Sc}$. This process leads to the conversion of low-angled subgrain boundaries to high-angled grain boundaries and the subsequent grain boundary sliding, which produces superplasticity. We proposed a model to describe grain boundary sliding accommodated by dislocation glide across grains with a uniform distribution of coherent precipitates. The model predicts the deformation rate is proportional to the stress raised to a second power, which is consistent with our experimental observation. It is noted that there have been more than ten papers on the superplasticity of Sc-containing alloys since we first pointed out the beneficial effect of Sc on grain refinement and strain rate enhancement in our paper in 1998. The recognition of our results is apparent.

Superplasticity and Creep of TiAl alloys (Relevant publications are listed in Appendix P2)

TiAlbased alloys are appealing for applications in advanced turbine engine components because of their low density, high specific strength and stiffness, and good environmental resistance at elevated temperatures. However, the poor fracture toughness and creep resistance has limited their applications. Fully lamellar TiAl alloys (with $\gamma$ 
and $\alpha_{2}$ lamellae) are now recognized to have good fracture toughness. However, there is still a strong need for the understanding of the creep mechanisms in these alloys.

To study creep of fully lamellar TiAl, we produced fully-lamellar TiAl (compositions in at. \%: Ti-47 Al-2Cr-2Nb) with a refined microstructure ( $\gamma$ lamellae: $100-300 \mathrm{~nm}$ thick, $\alpha_{2}$ lamellae: $10-50 \mathrm{~nm}$ thick) using powder metallurgy techniques. A nearly linear creep behavior (i.e. the steady-sate creep rate is linearly proportional to the applied stress) is observed when the alloy is creep deformed at low applied stresses ( $<400 \mathrm{MPa}$ ) and intermediate temperatures $\left(650-810^{\circ} \mathrm{C}\right)$. TEM examinations of the resulted deformation substructure revealed that interface sliding by the motion of pre-existing interfacial dislocations is the predominant deformation mechanism. This is because the operation and multiplication of lattice dislocations within both $\gamma$ and $\alpha_{2}$ lamellae are very limited in a low stress level as a result of a refined lamellar microstructure, creep mechanisms based upon glide and/or climb of lattice dislocations become insignificant. Instead, a cooperative glide of preexisting interfacial dislocations on both $\gamma / \alpha_{2}$ and $\gamma / \gamma$ interfaces (i.e. interface sliding) has found to be a predominant deformation mechanism. From the wavy appearance of interfacial dislocation lines and the measured activation energy for creep, we proposed that the viscous glide of interfacial dislocations dragged by solute (impurity) atoms controls the creep deformation of refined fully lamellar TiAl in the intermediate-temperature and low-stress regime. In the high stress regime, creep stress exponent is very high (greater than 7) and the formation and interaction of deformation twins in $\gamma$ phase become prevalent. Creep processes in this regime are complicated.

Another major challenge is associated with high temperature forming of TiAl since the alloy is brittle and difficult to machine. Superplastic forming is a viable technique to shape TiAl. However, it is important to perform the forming operation at a relatively low temperature $\left(<800^{\circ} \mathrm{C}\right)$. This is because the physical and mechanical properties of Ti-base alloys are extremely sensitive to the presence of oxygen.

To achieve low temperature superplasticity, we first produce the $\mathrm{Ti}-47 \mathrm{Al}-2 \mathrm{Cr}-1 \mathrm{Nb}-$ 1 Ta alloy with a metastable, equiaxed microstructure using a powder metallurgy technique. The starting microstructure of the alloy consists of an inhomogeneous mixture of $\gamma, \alpha_{2}$, and $\sim 50 \%$ by volume of soft $\beta$ grains. Tensile samples were tested at temperatures ranging from 650 to $1100^{\circ} \mathrm{C}$, and at strain rate ranging from $10^{-6}$ to $10^{-4}$ $\mathrm{s}^{-1}$. An elongation value of over $300 \%$ was obtained at a strain rate of $2 \times 10^{-5} \mathrm{~s}^{-1}$ and at a temperature as low as $800^{\circ} \mathrm{C}$, which is close to the ductile-to-brittle-transition temperature. From the fact that the measured strain rate sensitivity is about 0.5 , the dominant deformation mechanism is probably grain boundary sliding. During 
superplastic deformation (grain boundary sliding), the soft $\beta$ grains readily accommodate the sliding strain and also continuously convert into stable, equiaxed $\gamma+\alpha_{2}$ grains. This reduces the propensity for cavitation at grain triple junctions and, thus, delays the fracture process. Our study cleverly demonstrated the occurrence of superplasticity in a technological $\mathrm{TiAl}$ alloy $(\mathrm{Ti}-47 \mathrm{Al}-2 \mathrm{Cr}-2 \mathrm{Nb}$ ) with a metastable microstructure at a temperature as low as $800^{\circ} \mathrm{C}$ in air. The present discovery of low temperature superplasticity in TiAl has several important technological implications: examples include reduces tooling costs, reduced energy for forming, and minimized oxidation of products.

One final note on TiAl: the above creep and superplasticity studies were carried out using alloys with the same chemical composition. This illustrates the fact that microstructure dominates the properties of a TiAl alloy. Our studies showed that creep and superplasticity, a two apparently adverse properties, can be carefully manipulated via microstructural control.

Mechanical properties of bulk metallic glasses (Relevant publications are listed in Appendix P3)

Intensive efforts have been carried out over the past decade to develop bulk metallic glasses. This special class of materials has many potential applications resulting from their unique properties, such as superior strength and hardness, excellent corrosion resistance, shaping and forming in a viscous state, reduced sliding friction and improved wear resistance, and low magnetic energy loss. The mechanical behavior of metallic glasses is characterized by either inhomogeneous or homogeneous deformation. Inhomogeneous deformation usually occurs when a metallic glass is deformed at room temperature and is characterized by the formation of localized shear bands, followed by the rapid propagation of these bands, and sudden fracture. In contrast, homogeneous deformation in metallic glasses usually takes place at high temperatures $>0.70 \mathrm{~T}_{\mathrm{g}}$, where $\mathrm{T}_{\mathrm{g}}$ is the glass transition temperature), and the material can often exhibit extended plasticity. The extended plasticity is expected to lead to applications in the fields of nearshape fabrication of structural components.

Several studies have been recently conducted to characterize the homogeneous deformation behavior of bulk metallic glasses in the supercooled liquid region $\left(T_{\mathrm{g}}<\mathrm{T}<\mathrm{T}_{\mathrm{X}}\right.$, where $\mathrm{T}_{\mathrm{X}}$ is the crystallization temperature). Both Newtonian viscous flow and non-Newtonian behavior were reported. Theoretically, a Newtonian flow behavior, i.e. stress is linearly proportional to strain rate, is expected to be observed. It is, therefore, our purpose to carry out a study focusing on this discrepancy. We synthesized a 7.0-mm-diameter by $7.2 \mathrm{~cm}$-long $\mathrm{Zr}$-based (composition: $\mathrm{Zr}-10 \mathrm{Al}-5 \mathrm{Tr}-17.9 \mathrm{Cu}-14.6 \mathrm{Ni}$.) 
metallic glass. The alloys were prepared by arc melting in inert gas, followed by drop casting into $\mathrm{Cu}$ molds.

Plastic flow of a bulk amorphous $\mathrm{Zr}-10 \mathrm{Al}-5 \mathrm{Ti}-17.9 \mathrm{Cu}-14.6 \mathrm{Ni}$ alloy was characterized in the supercooled liquid region $\left(\sim 370\right.$ to $\left.450^{\circ} \mathrm{C}\right)$. Both strain rate cycling and strain rate decrease tests were performed to measure the strain rate sensitivity value of the alloy. The alloy has excellent mechanical formability in the supercooled liquid region. The alloy exhibited Newtonian behavior at low strain rates, but became nonNewtonian as the strain rate increases. Through collaboration with Dr. Gene Ice in Oak Ridge National Laboratory, X-ray diffraction was performed with both as-cast and deformed specimens. The specimens were measured on the Unicat beamline 33-ID at the Advanced Photon Source, Argonne National Laboratory. The beam size was 50x0 $0 \mu \mathrm{m}$. Results indicated that $\mathrm{Zr}_{2} \mathrm{Ni}$ nanocrystals (about $2.3 \mathrm{~nm}$ ) were formed in the sample deformed at $410^{\circ} \mathrm{C}$. The microstructures of deformed samples were further analyzed using high resolution TEM, through collaboration with Professor Hirotsu in Osaka University. The TEM results were consistent with that obtained from the $x$-ray diffraction. In addition, we found that there existed two different nanocrystal morphologies: isolated nanocrystals and nanocrystal clusters in amorphous matrix. Thus, even though tests were carried out in the supercooled liquid the region, nanocrystallization could still take place. The fact that the structure in the grip region remained amorphous but nanocrystallization occurred in the deformed region indicates that the nanocrystallization was stress driven. Therefore, the observed non-Newtonian behavior can be attributed to glass instability during deformation. We also develop a composite model to explain strain rate sensitivity values. In our study, we found that although multi-component BMG can be used as a precursor for nanocrystalline solids, however, nanocrystalline solids are not necessarily superplastic. The non-superplastic behavior is mainly caused by the great difficulty of strain accommodation at grain triple junctions. As an important final note: despite the discrepancy between Newtonian and non-Newtonian behavior, large tensile ductilities have been universally obtained in BMG in the supercooled liquid region. The large tensile ductility allows precision forming of this special class of corrosion-resistant materials for various functional devices, e.g. microgears for bioimplants. 


\section{Appendix A \\ Peer-reviewed archival publications (FY 98-01)}

\section{P1 - Superplasticity of AfMg based and $\mathrm{Mg}$ alloys}

1. T. Mukai, H. Iwasaki, K. Higashi, and T.G. Nieh, 'Superplasticity in a DoublyExtruded Magnesium Composite (ZK60/SiC/17p),' Mater. Sci. Technol., 14, 32-35, ' (1998).

2. E.M. Taleff, G.A. Henshall, T.G. Nieh, D.R. Lesuer, and J. Wadsworth, 'WarmTemperature Tensile Ductility in Al-Mg Alloys,' Metall. Mater. Trans., 129A(3A), 1081-1091 (1998).

3. T.C. Schulthess, P.E.A. Turchi, A. Gonis, and T.G. Nieh, 'Systematic Study of Stacking Fault Energies of Random Al-Based Alloys,' Acta Mater., 46(6), 22152221 (1998).

4. T.G. Nieh, L.M. Hsiung, J. Wadsworth, and R. Kaibyshev, 'High Strain Rate Superplasticity in a Continuously Recrystallized Al-6\% Mg-0.3\%Sc Alloy,' Acta Mater. 46(8), 2789-2800 (1998).

5. M.E. Kassner, T.G. Nieh, D.A. Hughes, M.G. Stout, and J.S. Vetrano, 'Metal Forming at the United States Department of Energy Center of Excellence for the Synthesis and Processing of Advanced Materials,' la Metallurgia italiana 90 (12), 37-45, (1998).

6. H. Watanabe, T. Mukai, T.G. Nieh, and K. Higashi, 'Low-Temperature Superplasticity in a Magnesium-Based Composite,' Scr. Mater, 42(3), 249-255 (2000).

7. S. Namilae, C. Shet, N. Chandra, and T.G. Nieh, 'Atomistic Simulation of the Effect of Trace Elements on Grain Boundary of Aluminum,' Mater. Sci. Forum, 357-359, 387-392 (2001).

8. R. Kaibyshev, I. Kazakulov, D. Gromov, F. Musin, D.R. Lesuer, and T.G. Nieh, 'Superplasticity in a 2219 Aluminum Alloy,' Scr. Mater. 44 (10), 2411-2417 (2001).

9. J. Wang, L.M. Hsiung, T.G. Nieh, and M. Mabuchi, 'Creep of a Heat-Treated $\mathrm{Mg}-4 \mathrm{Y}-3 \mathrm{RE}$ Alloy,' Mater. Sci. Eng. A, 315 (1-2), $81-88$ (2001).

\section{P2 - Superplasticity and Creep of TiAl alloys}

1. J.N. Wang and T.G. Nieh, 'The Role of Ledges in Creep of TiAl Alloys with Fine Lamellar Structures,' Acta Mater., 46(6), 1887-1901 (1998).

2. J.G. Wang, L.M. Hsiung, and T.G. Nieh, 'Formation of Deformation Twins in a Crept Lamellar TiAl Alloy,' Scr. Mater. 39(7), 957-962 (1998). 
3. T.G. Nieh, L.M. Hsiung, and J. Wadsworth, 'Superplastic Behavior of a PowderMetallurgy TiAl Alloy with a Metastable Microstructure,' Intermetallics, Z, 163170 (1999).

4. J.G. Wang, L.M. Hsiung, and T.G. Nieh, 'Microstructural Instability in a Crept Fully Lamellar TiAl Alloy,' Intermetallics, 7(7), 757-763 (1999).

5. L.M. Hsiung and T.G. Nieh, 'Creep Deformation of Fully-Lamellar TiAl Controlled by the Viscous Glide of Interfacial Dislocations,' Intermetallics, 7(7), $821-827$ (1999).

6. T.G. Nieh and J. Wadsworth, 'Fine-Structure Superplastic Intermetallics,' International Materials Review, 44(2), 59-75 (1999).

7. J. Wang and T.G. Nieh, 'Creep of a Beta Phase-Containing TiAl Alloy,' Intermetallics, 8(7), 737-748 (2000).

8. T.G. Nieh, J.G. Wang, and C.T. Liu, 'Deformation of a Multiphase Mo-9.4Si13.8B Alloy at Elevated Temperatures,' Intermetallic, 9(1), 73-79 (2001).

9. W.J. Zhang, G.L. Chen, F. Appel, T.G. Nieh, and S.C. Deeve, 'A Preliminary Study on the Creep Behavior of a Ti-45Al-10Nb Alloy,' Mater. Sci. Eng. A, 315 $(1-2), 250-253(2001)$.

P1 - Mechanical properties of bulk metallic glasses

1. T.G. Nieh, T. Mukai, C.T. Liu, and J. Wadsworth, 'Superplastic Behavior of a $\mathrm{Zz}-10 \mathrm{Al}-5 \mathrm{Ti}-17.9 \mathrm{Cu}-14.6 \mathrm{Ni}$ Metallic Glass in the Supercooled Liquid Region,' Scr. Mater. 40(9), 1021-1027 (1999).

2. J.G. Wang, B.W. Choi, T.G. Nieh, and C.T. Liu, 'Crystallization and Nanoindentation Behavior of a Bulk $\mathrm{Zr}-\mathrm{Al}-\mathrm{Ti}-\mathrm{Cu}-\mathrm{Ni}$ Amorphous Alloy,' $J$. Mater. Res., 15(3), 798-807 (2000).

3. J. G. Wang, B. W. Choi, T. G. Nieh, and C.T. Liu, 'Nano-Scratch Behavior of a Zr-Based Bulk Amorphous Alloy,' J. Mater. Res., 15(4), 913-922 (2000).

4. F.G. Shi, T.G. Nieh, and Y.T. Chou, 'A Free Volume Approach for SelfDiffusion in Metals,' Scr. Mater. 43(3), 265-267 (2000).

5. P. Asoka-Kumar, J. Hartley, R. Howell, P.A. Sterne, and T.G. Nieh, 'Chemical Ordering around Open-Volume Regions in Bulk Metallic Glass $\mathrm{Zr}_{52.5} \mathrm{~T}_{5} \mathrm{Al}_{10} \mathrm{Cu}_{17.9} \mathrm{Ni}_{14.6}$,' Appl. Phys. Lett., 77(13), 1973-1975 (2000).

6. T.G. Nieh, J. Wadsworth, C.T. Liu, G.E. Ice, and K.-S. Chung, 'Extended Plasticity in the Supercooled Liquid Region of Bulk Metallic Glasses,' Mater. Trans. JIM, 42(4), 613-618 (2001).

7. T.G. Nieh, J. Wadsworth, C.T. Liu, Y. Ohkubo, and Y. Hirotsu, 'Plasticity and Structure Instability in a Bulk Metallic Glass Deformed in the Supercooled Liquid Region,' Acta Mater. 49(15) 2887-2896 (2001).

Nanostructured materials and thin films 
1. T.G. Nieh, T.W. Barbee, and J. Wadsworth, 'Tensile Properties of a FreeStanding Cu/Zr Nanolaminate,' Scr. Mater., 41(9), 929-935 (1999).

2. S. Suresh, T.G. Nieh, and B.W. Choi, 'Nano-Indentation of Copper Thin Films on Silicon Substrates,' Scr. Mater., 41(9), 951-957 (1999).

3. Mikrajuddin, F.G. Shi, T.G. Nieh, and K. Okuyama, 'Metal-to-Semiconductor Transition in Nanocrystals: Size and Temperature Dependence,' Microelectronics $J ., \underline{31(5)}, 343-351$ (2000).

4. J. Wang, H.K. Kim, F.G. Shi, B. Zhao, and T.G. Nieh, 'Thickness Dependence of Morphology and Mechanical Properties of on-Wafer Low-k PTFE Dielectric Films,' Thin Solid Films, 377, 413-417 (2000).

5. T.G. Nieh and J. Wadsworth, 'High Strength Freestanding Metal-Amorphous Multilayer,' Scr. Mater. 44 (8-9), 1825-1830 (2001).

\section{Deformation of Metallic foams}

1. T.G. Nieh, J. Kinney, A.J.C. Ladd, and J. Wadsworth, 'Morphology and Elastic Properties of Aluminum Foams Produced by a Casting Technique,' Scr. Mater., 38(10), 1487-1494 (1998).

2. T. Mukai, H. Kanahashi, T. Miyoshi, M. Mabuchi, T.G. Nieh, and K. Higashi, 'Experimental Study of a Closed-Cellular Aluminum Foam for Energy Absorption under Dynamic Loading,' Scr. Mater. 40(8), 921-927 (1999).

3. T. Mukai, H. Kanahashi, Y. Yamada, K. Shimojima, M. Mabuchi, T.G. Nieh, and K. Higashi, 'Dynamic Compressive Behavior of an Ultra-Lightweight Magnesium Foam,' Scr. Mater. 41(4), 365-371 (1999).

4. H. Kanahashi, T. Mukai, Y. Yamada, K. Shimojima, M. Mabuchi, T.G. Nieh, and K. Higashi, 'Dynamic Compression of an Ultra-Low Density Aluminum Foam,' Mater. Sci. Eng,. 280A(2), 349-353 (2000).

5. T.G. Nieh, K. Higashi, and J. Wadsworth, 'Effect of Cell Morphology on the Compressive Properties of Open-Cell Aluminum Foams,' Mater. Sci. Eng., 283A, $105-110(2000)$.

\section{Proposed statement of work and technical approach}

We studied superplasticity in microcrystalline, subcrystalline, and even amorphous materials in recent years, and have developed significant understanding in the mechanisms and microstructure-deformation relationship. The study of nanocrystalline materials (with grain size $\sim 10-50 \mathrm{~nm}$ ) has been hindered by the availability of the materials. However, this barrier is gradually removed by the recent progress in the development of nanocrystalline materials. It is now the right time to examine nanostructured materials to bridge the gap between microcrystalline and amorphous 
materials. Intriguing questions immediately arise: do the deformation mechanisms prevail in microcrystalline or amorphous materials also extend to nanocrystalline regime? If not, what are the new mechanisms?

For example, when the grain structure of a material is refined from microcrystalline to nanocrystalline, several challenging questions are raised. Questions such as; at what length scale the classical Hall-Petch (HP) relationship is broken down? What is the controlling deformation and fracture mechanism in materials with a grain size in the nanometer range? At what length scale does deformation shift from lattice-dislocation control to grain-boundary control? Specifically, is grain boundary sliding, which is the dominant superplastic deformation mode in microcrystalline alloys, still prevalent in nanocrystalline materials? In fact, OBES recently formed a study group to investigate the mechanisms contributing to the inverse Hall-Patch relationship using computational methods. Furthermore, nanocrystalline materials (nc-materials) are, in theory, brittle because there is a lack of hardening mechanism. However, Lu and coworkers [1] recently made an exceptional observation. They produced high-purity, fully dense, nanocrystalline ( $\sim 30 \mathrm{~nm}$ grain size) $\mathrm{Cu}$ in bulk form $(\sim 2 \mathrm{~mm}$ thick) using an electrodeposition technique. The material has a room temperature tensile ductility of $\sim 30 \%$ ! It shows a high strain hardening exponent $(\sim 0.22)$ in the as-deposited condition, but exhibits virtually no strain hardening effect once it is deformed to a large strain [2]. As a result, it can be continuously cold rolled at room temperature up to over $5000 \%$ strain [2]. Now, an immediate question $\dot{\mathrm{s}}$ : why were Lu's $n c$-materials ductile while others, some also produced by electrodeposition, were brittle? The observed plasticity must be associated with a "special" microstructure. To date, two deformation mechanisms have been proposed for nc-materials; diffusional creep [3] and grain boundary sliding [4]. However, no direct experimental evidence exists to support either theory. It seems difficult to envision that diffusional rate is sufficiently fast at room temperature to contribute to large deformation. Similarly, macroscopic grain boundary sliding, which involves the cooperative transport of atoms, is probably difficult to take place also. Even though the underlying deformation mechanisms are yet-to-be understood, the experimental results of $\mathrm{Lu}$ et al are sufficient to warrant an extensive investigation of $n c$-materials. Thus, we propose to expand our current research project from microcrystalline to nanocrystalline materials in hope to address some of the outstand ing scientific questions.

The proposed research couples theory and experiments with an emphasis on materials of macroscopic dimensions $(\mathrm{mm}-\mathrm{cm})$ that are composed of nanoscale $(<100 \mathrm{~nm})$ grains. It is organized into three major areas: 
Synthesize nanocrystalline materials with grain size in the range $5-100 \mathrm{~nm}$ range using electrodeposition method.

Carry out subsequent experimental studies to probe microstructural evolution and mechanisms of mechanical deformation and failure in these nanostructured materials.

Use large-scale simulation and multiscale modeling technologies to provide insight to deformation mechanisms that may not be observable experimentally. Check the results obtained from multiscale modeling, comparing experimental observations with results with those obtained from atomistic, dislocation-based, crystal plasticity, and continuum simulations that cover the spectrum of mechanisms.

The specific technical approach to accomplish the above tasks is described as follows.

\section{Material Synthesis}

One of the major challenges to study $n c$-materials is that it is difficult to synthesize this special class of material in a controllable fashion and in sufficient quantity for investigation. We will exclude powder metallurgy techniques since many evidences indicate the great difficulties to eliminate defects in $n c$-materials produced by powder processing. Then, there are essentially three one-step processing routes to produce $n c$ materials: severe plastic deformation (Equal Channel Angular Extrusion), nanocrystallization from bulk amorphous alloys, and deposition. Based upon the intriguing results of $\mathrm{Lu}$ et al, electrodeposition method is proposed in the present project. We will use the technique to produce nanocrystalline $\mathrm{Ni}(\mathrm{fcc})$ and $\mathrm{Fe}$ (bcc) with various grain sizes in the range $5-100 \mathrm{~nm}$ because this is the grain size range that has rarely been explored, both experimentally and theoretically. The total thickness of the deposit is in mm range. Materials will be produced with a range of grain sizes starting with $30 \mathrm{~nm}$ and progressing to smaller and larger sizes. We anticipate the possibility that the lower limit of grain size may be material dependent with copper being of the order $20 \mathrm{~nm}$. We expect to produce significantly smaller grain sizes $(\sim 6 \mathrm{~nm})$ in nickel [5]. Pure iron can be produced at sizes down to $\sim 20 \mathrm{~nm}[6]$. The control of solution $\mathrm{pH}$ has been demonstrated [7] to be able to fabricate a range of grain size in nanocrystalline Ni by electrodeposition without using additives that can cause adverse effects and compromise the purity of the deposit. An inverse HP relation is predicted to occur in the grain size range of about 10$20 \mathrm{~nm}$ [8]. The determination of the exact grain size at which HP breaks down is an important task because this allows us to determine the maximum strength of an ncmaterial. 


\section{Experiment}

The mechanical properties, in tension, compression, and possibly torsion and fatigue, will be conducted at different strain rates $\left(1 \times 10^{-4}-10^{4} \mathrm{~s}^{-1}\right)$ and temperatures $(70 \mathrm{~K}-300 \mathrm{~K})$ to probe the deformation mechanism and examine possible yield asymmetry. In view of the fact that the yielding of amorphous alloys obeys Mohr-Coulomb not Von Mises criterion, we expect that the yielding of a nanocrystalline solid would be more Coulomb as the grain size decreases finer. A direct comparison of tension and compression data would allow us to observe whether there is a yield asymmetry. Nanoindentation will also be used for characterizing the modulus, hardness (i.e. strength), yielding, residual stresses, and wear (tribological) properties of $n c$-materials. In addition, the technique can be applied to study indentation creep. Creep process is particularly pertinent to $n c$ materials since a large volume fraction of grain boundary is expected to accelerate creep at room temperature. We have in house both NanoIndenterXP and TriboIndenter for this study.

As mentioned before, an outstanding question exists as to why Lu's materials are ductile. Grain boundary sliding and rotation are generally believed to contribute to plasticity in fine-grained materials. These processes are closely related to the grain boundary and triple junction structures. Lu reported that the grain boundaries in their electrodeposited $n c-\mathrm{Cu}$ were mainly low-angle but evolved into high-angle after deformation. Thus, to investigate plasticity in $n c$-materials, it is important to characterize the boundary structures prior, during, and after deformation. The extent to which dislocations play a role in the deformation, their interaction with the boundaries and triple junctions, and the role of boundaries in plasticity will be studied by in situ experiments. These include in situ straining in an electron backscatter diffraction set-up to map grain motion and reorientation during deformation (limited to studies in $\mathrm{Au}$ [9]) and transmission electron microscopy (TEM) to better resolve the contribution of grain boundaries and triple junctions to the deformation process. Impurity segregation occurs in any "high-purity" material, particularly in grain boundaries. Impurities can affect the mobility of grain-boundary dislocations. The nature and distribution of these impurities will be examined using high-resolution TEM attached with a nano-probe $(\sim 0.5 \mathrm{~nm}$ probe size). Atom probe field emission microscopy (APFIM) will also be used to identify grain boundary impurities in nc-materials. This high spatial resolution technique enables the presence of ultrafine scale inhomogeneities that may occur in the material due to solute, precipitation, clustering, and chemical short range ordering to be detected and characterized. Fracture mode of $n c$-materials will be identified primarily using atomic force microscopy (AFM). An SEM, even attached with a field-emission gun, has a 
resolution limit greater than $10 \mathrm{~nm}$. Since deformation in $n c$-materials occurs primarily in grain boundaries, we expected fracture takes place predominantly intergranular.

Synchrotron $x$-ray diffraction techniques [10] have been demonstrated to yield information on the dislocation activity and grain size in $n c$-materials. We will use these peak profile analysis techniques to detect dislocations as well as void or cavity formation. The experiment can not only provide information on plasticity but also shed light on fracture processes in $n c$-material. Whether fracture takes place by void formation and coalescence or by plastic tearing (cracking), and occurs at which type of boundaries will be examined. Positron annihilation spectroscopy will be employed to study the early onset of void formation during failure. Localized shear banding has previous reported during the fracture of many $n c$-materials. Therefore, special efforts will be made to study shear band formation and propagation. To understand fracture processes is important for the establishment of the fracture criterion in $n c$-materials. Such information is also useful for atomistic or molecular dynamic simulations.

Nanostructures are often non-equilibrium and contain large residual stresses. As a result, anelastic relaxation can readily occur in $n c$-materials. In this project, we will measure the anelastic displacements of specimens using laser interferometry (Nd: YAG laser with resolution around $50 \mathrm{~nm}$, as compared to a total anelastic relaxation of about 1$2 \mathrm{~mm}$ ). The measurements will be carried out at different temperatures. However, it is pointed out that these measurements would not tell us whether grain boundary sliding is the dominant mechanism for relaxation. To evaluate the contribution caused by grain boundary sliding, internal friction experiment will be conducted using Dynamic Mechanical Analyzer. The internal friction will be determined with respect to grain size, temperature (e.g. $-100^{\circ} \mathrm{C}$ to $+100^{\circ} \mathrm{C}$ ), and frequency. The occurrence of grain boundary sliding at room temperature can be confirmed from this study. Another possible technique to study grain boundary sliding is to perform in situ SEM tensile experiment. However, as noted before, this technique is limited to grain sizes greater than $10 \mathrm{~nm}$.

\section{Simulation}

While systematic and controlled experiments provide valuable insights and a basic framework to develop fundamental knowledge of the mechanical properties and mechanisms in $n c$-materials, the development of a broad quantitative predictive capability, useful for practical design purposes, is not possible without parallel simulation and modeling efforts. Such efforts should inevitably seek to include the entire spectrum of length scales, from the atomistic/molecular to the continuum levels through the dislocation and crystalline levels. There are four different levels of multiscale modeling in the study of $n c$-materials: atomistic and molecular dynamics simulations, mechanism- 
based dislocation level models, continuum and discrete deformation processes associated with crystal plasticity, and analytical, mechanistic and computational models for fracture. The experimental results are extremely useful for validating simulations at different length scales. However, it is noted that experiments in the grain size range of $<15 \mathrm{~nm}$ are difficult to perform. Simulation may be the only way to extend our understanding of $n c$ materials to a grain size $<15 \mathrm{~nm}$.

As a first step in understanding the mechanisms occurring at the atomic scale we will perform large-scale (10s of millions of atoms) molecular dynamics (MD) simulations using the LLNL ASCI White, the fastest computer in the world. Existing calculations with relatively small-scale ( millions of atoms) have been able to achieve only grain sizes up to $12 \mathrm{~nm}$ with 3D grains [11, Van Swygenhoven, 1999 \#727]. Larger grain sizes have been achieved using 2D grains [12]. These calculations suggested some possible atomic processes during deformation, but more questions arise. Questions such as the effect of grain size distribution or 3D grains larger than $12 \mathrm{~nm}$ are difficult to answer without invoking calculations. We will address some of these questions by focusing on five variables: (1) grain boundary type (2) grain size (3) impurity segregation (4) temperature and (5) material type (Ni, and $\mathrm{Fe}$ ) parallel to the experiments described above. We will explore the atomistic processes occurring in systems with low angle grain boundaries and mixed low- and high-angle boundaries, in an effort to understand the experimental observations of $\mathrm{Lu}$ and co-workers. We will start with a system with an average grain size of $30 \mathrm{~nm}$. Previous simulations performed in Ni with $12 \mathrm{~nm}$ average grain sizes [4] and recently with 20nm grains [13] have shown the possible emission of partial dislocations from the grain boundaries. However the emission of a second partial was not observed. A larger grain size simulation is expected to reveal some unseen phenomena. These MD simulations, the largest of this type, will help us to explore the transition between processes dominated by dislocation and by grain boundary mechanisms, that is, the limit of the Hall-Petch relationship. Impurities can also play an important role in deformation. For instance, grain boundary impurity segregation affects grain boundary dislocation motion. We will use the interatomic potentials developed by Professor Diana Farkas for $\mathrm{Fe}, \mathrm{Al}, \mathrm{C}$, and $\mathrm{H}$ in $\mathrm{Ni}$ to study the effect of impurities in grain boundary sliding.

Full-atomistic simulations are powerful in revealing collective mechanisms occurring in nanocrystalline materials. However, one of the major limitations of these simulations is the high strain rate applied, usually several orders of magnitude larger than the highest achieved experimentally. This implies that some of the slowest processes are suppressed in these simulations. In an effort to approach the experimental strain rates we will use 
two methods: for the smallest grain sizes (up to $10 \mathrm{~nm}$ ) we will use parallel replica dynamics methods in order to extend the simulation time [14]. However, this method will not be applicable to the largest grain sizes. In this case we will use full atomistic simulations to isolate individual processes (dislocation emission, grain rotation, grain boundary sliding). We will use smaller simulation cells, where longer times can be achieved, to study isolated processes such as grain boundary migration and sliding. All these different mechanisms will be included into a continuum model to study the collective effect in an $n c$-material. With this simulation model we will be able to study the effect of strain rate, and isolate the most important processes occurring at different strain rates. Finally, a simulation capability, based on the quasi-continuum approach [15] can be used to study phenomena occurring at the largest grain sizes $(100 \mathrm{~nm})$ with grain size distributions comparable to experimental measurements. 


\section{References}

1. L. Lu, L.B. Wang, B.Z. Ding, and K. Lu, J. Mater. Res., 15(2) (2000) 270.

2. L. Lu, M.L. Sui, and K. Lu, Science, 287 (2000) 1463.

3. B. Cai, Q.P. Kong, L. Lu, and K. Lu, Scr. Mater., 41(7) (1999) 755.

4. H. Van Swygenhoven, M. Spaczer, and A. Caro, Acta Mater., 47(10) (1999) 3117.

5. N. Wang, Z.R. Wang, K.T. Aust, and U. Erb, Acta Metall. Mater., V43(N2) (1995) 519.

6. M.L. Trudeau, NanoStru. Mater., 12 (1999) 55.

7. F. Ebrahimi, G.R. Bourne, M.S. Kelly, and T.E. Mathews, NanoStructured Mater., 11(3) (1999) 343.

8. T.G. Nieh and J. Wadsworth, Scr. Metall. Mater., 25 (1991) 955.

9. F. Cosandey, Microscopy \& Microanalysis, 3(4) (1997) 559.

10. T. Ungar, S. Ott, P.G. Sanders, A. Borbely, and J.R. Weertman, Acta Mater., 46(10) (1998) 3693.

11. J. Schiotz, T. Vegge, F.D.D. Tola, and K.W. Jacobsen, Phys. Rev. B, 60(17) (1999) 11971.

12. V. Yamakov, D. Wolf, M. Salazar, S.R. Phillpot, and H. Gleiter, Acta Mater., 49(14) (2001) 2713.

13. H.V. Swygenhoven, P. Derlet, and M.J. Caturla, Phys. Rev. B, (2001) - in press.

14. A.F. Voter, Phys. Rev. B, 57 (1998) R13986.

15. E.B. Tadmor, M. Ortiz, and R. Phillips, Phil Mag. A, 73 (1996) 1529. 
Appendix B

Meetings and symposia organized based on OBES/DMS\&E support:

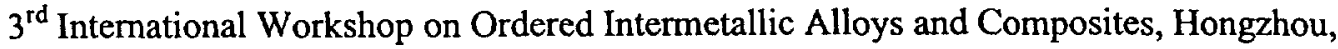
China, April 5-10, 1998. (with C.T. Liu, Steve Sass, D.L. Lin)

The Fifth IUMRS International Conference on Advanced Materials - Symposium D: Intermetallic Compounds and Bulk Metallic Glasses - Beijing, People's Republic of China, 13-18

June 1999. (with C.T. Liu, G.L. Chen, A. Inoue, S.K. Wu, and R. Ritchie)

International Conference on Bulk Metallic Glasses, sponsored by United Engineering

Foundation, Singapore, September 24-28, 2000, (with C.T. Liu, W.D. Nix, A. Inoue, and

Y. Li)

\section{Appendix C}

Facility and special equipment for this study

A number of special analytical tools are to be used for characterizing nanostructured materials and metallic glasses. These state-of-the-art techniques also developed under BES programs exist in different DOE laboratories and our proposed experiments will be carried out primarily on a collaborative basis. The applicability of these techniques to the study of the various aspects of deformation behavior is described as follows.

Positron Annihilation Spectroscopy (PAS)

Positron annihilation spectroscopy (PAS) is a sensitive probe for studying defects in solids. Conventional PAS measurements for defect characterization generally utilize two observables: positron lifetime and the conventional Doppler broadening of the annihilation gamma rays using a single detector. Neither of these techniques is sensitive to elemental variations around an annihilation site, such as the one occurring when a material is lightly doped or when a vacancy is tied with an impurity atom. A third observable, angular correlation of annihilation radiation, can overcome this deficiency. However, this observable is not used routinely in defect spectroscopy owing to the difficulties associated with the low counting rates at many of the existing facilities. LLNL recently installed a new two-detector coincidence system to examine the line shape variations originating from high-momentum core electrons. The highmomentum part of the Doppler-broadened annihilation spectra can be used to 
distinguish different elements around an annihilation site. The new setup improves the peak to background ratio in the annihilation spectrum to $\sim 10^{-2}$, and as a result the variations of the Doppler-broadened spectra resulting from annihilations with different core electrons can be mapped. Because the core electrons retain their atomic character even when atoms form a solid, the new results can be easily verified with straightforward theoretical calculations. This new PAS will be used to probe the nature of volumetric defects (e.g. void) and clusters, e.g. size, distribution, and chemical composition. This will be done on samples both before and after plastic deformation. We will also perform in situ straining experiments to examine defect evolution during deformation.

\section{High Resolution Electron Microscopy (HREM)}

Atomic resolution electron microscopy is a powerful method for the characterization of atomic and lattice arrangements and ordering. We have a Philips CM300FEG super twin S/TEM. This $300 \mathrm{Kev}$ field emission transmission electron microscope is equipped with and analytical pole piece having a resolution of $1.9 \AA$ and information limit of $1.2 \AA$. The EDS system has a thin window for light element detection and is controlled by an EMISPEC software system having line scan and elemental mapping capability. The PEELS and camera system is a GIF system from Gatan Inc. The GIF is capable of acquiring images and energy filtered elemental maps up to $2 \mathrm{~K} \times 2 \mathrm{~K}$ pixels and energy loss spectra, and additionally incorporates a TV rate digital camera for live viewing. The specimen holders consist of an analytical double tilt stage, a single tilt heating straining stage, a vacuum transfer double tilt stage and a LN2 cryotransfer double tilt stage. Studies will carried out to characterize grain boundary impurity and dislocation structures in nc-materials using HREM combined with an Z-contrast Phase Analysis technique. We also plan to carry out in situ straining experiments to study the grain boundary dislocation-impurity interaction.

\section{Atom Probe Field Ion Microscopy (APFIM)}

Atom probe field ion microscopy (APFIM) is a technique that enables the detection of ultrafine scale inhomogeneities that may occur in the material due to impurity segregation, precipitation, clustering, and chemical short range ordering. For example, small scale phase separation and crystallization may be detected by dividing the atom-by-atom data into small blocks and calculating the composition of each block, thereby creating a composition profile for amorphous $\mathrm{Zr}-10 \% \mathrm{Al}-5 \% \mathrm{Ti}-17.9 \% \mathrm{Cu}-14.6 \% \mathrm{Ni}$. These composition profiles can be used as 
the input to a variety of standard statistical tests. Statistical tests based on Markov chain techniques can be applied to the atom probe data from metallic glasses to detect clustering and chemical short range order of the alloying elements. Through these tests the order of the adjacent atoms in the ion-by-ion data chain can be examined and compared to expected values for a random solid solution. The Johnson and Klotz ordering parameter, ? , can be determined from the number of $A B$ and $B B$ pairs in the data chain, where $B$ is the atom of the element of interest and $A$ is any other atom. If ? $>1$, the data contains more $B B$ atom pairs than expected in a random solid solution and suggests that the material contains solute clusters. If ? $<1$, the number of $B B$ atoms in the data chain is significantly less and the number of $A B$ pairs is greater than that expected in a random alloy and suggests the presence of chemical short-range order. The data chain may be further examined for $A B A, A B B A$, etc. chains. If the number of $A B A$ is larger than expected, the alloy exhibits chemical shortrange order whereas, if the number of $A B B A$ and longer chains is larger than expected then the alloy exhibits clustering. In the present project, one of the most important issues is the grain boundary impurity and precipitates and their effects on deformation. APFIM is an extremely useful technique for identifying the impurities. Dr. Mike Miller of ORNL will be our collaborator.

\section{Small Angle Neutron Scattering (SANS)}

Small-Angle Neutron Scattering (SANS) is another useful technique in investigating nanostructure or short-range order (SRO) in metallic glasses. In fact, the real-space information obtained by APFIM is an excellent complement to the reciprocal-space information extracted from SANS data. The complementary use of these two techniques offers a valuable approach to the study of structural relaxation in bulk metallic glasses. While pulse neutron sources in IPNS at ANL or LANSCE at LANL may be useful for obtaining atomic PDF of a BMG, the SANS facility at ORNL is more suitable for the study of the role of phase separation associated with mechanical behavior of metallic glasses. We will therefore use the SANS to characterize the structural relaxation behavior of $\mathrm{Zr}$ 10Al-5Ti-18Cu-15Ni alloys of three different purity levels (i.e. very high purity, commercial purity, and microalloyed state). The 30-m SANS camera with position sensitive area detector is currently being reconfigured as an interim 12$m$ instrument to allow construction of the new cold guide hall. A 35-m SANS will be one of the new instruments with cold source. Because of the long neutron guides between the cold source and the detector tube, neutron flux at a specimen 
will be in excess of $10^{7} \mathrm{n} /\left(\mathrm{cm}^{2}-\mathrm{s}\right)$ which is about two orders of magnitude higher than that at the old 30-m camera. Temperature and magnetic field dependence of SANS profiles will be obtained to see if there is any neutron scattering of magnetic origin from amorphous phases. The effect of hydrostatic pressure on structural relaxation will be tested by using the pressure cell (up to $1 \mathrm{kbar}$ ) with temperature control (up to $250^{\circ} \mathrm{C}$ ). Because of the wide wavelength range of ? ? = 0.5-2.0 nm, atomic structure and microstructural relaxation behavior in $\mathrm{Zr}$ base bulk amorphous alloys can be characterized statistically for structural features ranging from 1 to $500 \mathrm{~nm}$. The direct information on chemical composition and morphology of the second amorphous phase is a very important input in the convolution analysis of the size distribution of scattering centers based on the neutron scattering cross section. This can be provided by the parallel APFIM research using the same set of Zr-base BMG alloy samples.

\section{Nanoindenter}

A nanoindenter is an instrument used to characterize a material's mechanical properties using extremely small volumes of material. The diamond indenter tip has a displacement resolution of less than $0.2 \mu \mathrm{m}$, and a maximum indentation depth of $500 \mu \mathrm{m}$. LLNL has a Nano Indenter XP equipped with a DCM (Dynamic Contact Module) and TriboIndenter (Hysitron). The DCM is an indentation head which has a maximum force capability of only $10 \mathrm{mN}$, and load resolution of $1 \mathrm{nN}$; it is specifically designed for ultra-low load indentation work. The DCM has not only an ability to accurately apply and measure smaller loads and displacements than the standard head, but its unique dynamic design gives it a resonant frequency 10 times higher and a damping coefficient 100 times lower. This greatly enhances the signal to noise ratio allowing more accurate measurements. Nanoindentation has been suggested for estimating residual stresses. The XP/DCM will be used for residual stress measurements since hardness values as a function of indentation depth provide an estimate of residual stress, as a result of various deposition conditions. Nanoindentation can also be used to probe the yielding behavior of nano-structured materials. In addition, tribological properties (e.g., friction coefficient) of both $n c$-materials and metallic glasses can be obtained from scratch tests using the nanoindenters. The attached AFM on the TriboIndenter would allow us to examine in situ the indentation or scratch morphologies. 


\section{Computing- ASCI White}

The ASCI platforms at Lawrence Livermore National Laboratory are the IBM SP ASCI Blue-Pacific and the IBM SP ASCI White. ASCI Blue has 256 nodes with 4 processors per node (a total of 1024 processors) for unclassified computing, with a processor speed of $332 \mathrm{MHz}$ and memory per node of $1.536 \mathrm{~GB}$, and a theoretical peak performance of 664 Mflops per processor. Within the classified computing ASCI White has 512 nodes and a total of 8192 processors. This system is currently ranked as the world's fastest computer, with a peak speed slightly greater than $12 \mathrm{TeraOP} / \mathrm{s}$ (see_http://www.llnl.gov/asci/news/white news.html). Other platforms that belong to ASCI are ASCI Red at Sandia National Laboratory and ASCI Blue Mountain at Los Alamos National Laboratory. ASCI white is readily available for $u$ s to simulate the deformation of $n c$-materials with grain size near $20 \mathrm{~nm}$ and $\sim 8 \times 10^{-6}$ atoms.

\section{Scientific collaborators}

Dr. Rich Howell, Lawrence Livermore National Laboratory

- Positron annihilation study to characterize volumetric defects in metallic glasses

Dr. C.T. Liu, Oak Ridge National Laboratory

- Mechanical properties of metallic glasses

Dr. Jim Ice, Oak Ridge National Laboratory

- X-ray diffraction of nanostructured materials

Dr. John Vetrano, Pacific Northwest National Laboratory

- Microstructural characterization of superplastic AlMg alloys

Professor Oleg D. Sherby, Stanford University

- General superplasticity in metals and ceramics

Professor Subra Suresh, MIT

- Nanoindentation of nanostructured and amorphous materials

Professor Frank Shi, University of California - Irvine

- Kinetics of Nanocrystallization of amorphous alloys

Professor Mike E. Kassner, Oregon State University

- Superplasticity and formability of AHg based alloys

Professor Kenji Higashi, Osaka Prefecture University, Japan

- High strain rate superplasticity in aluminum and magnesium alloys 


\section{Professor Yoshi Hirotsu, Osaka University, Japan}

- High resolution transmission electron microscopy of amorphous and nanostructured materials

Professor Rustam Kaibyshev, Institute of Superplasticity, Russia

- Characterization of superplastic properties of aluminum alloys 


\section{Curriculum Vitae}

Tai-Gang (TG) Nieh

http://www-cms.llnl.gov/bios/niehbio.html

Dr. T.G. Nieh is currently a Senior Scientist in the Chemistry and Materials Science Directorate, Lawrence Livermore National Laboratory (LLNL), responsible for initiating and conducting research programs funded by the U.S. government. He is currently the Principal Investigator of $R \& D$ programs, including "Deformation Behavior of Metastable, Multi-component Systems", sponsored by U.S. DOE-Office of Basic Energy Science; "Enhancement of Strength and Ductility in Bulk Nanocrystalline Metals", sponsored by LLNL Laboratory-Directed Research and Development Program; "Development of Cellular Hydroxyapatite for Biomedical Applications", sponsored by LLNL Laboratory-Directed Research and Development Program. He also provides technical supports/consultations to several LLNL programs, including NIF and Yucca Mountain (Nuclear Waste Management-Ceramics Immobilization).

Prior to joining LLNL, he was a Senior Fellow and Group Leader of the Metallurgy Department, Research and Development Division, Lockheed Missiles and Space Co. During the twelve years with Lockheed, he was the Principal Investigator for a long-standing Independent Research and Development project - Innovative Materials Development, which included research activities, such as Superplasticity, Laminates, High Rate Deformation, Intermetallic Alloys and Composites, Nanocrystalline Materials, Light-weight Alloys, and Refractory Metals. He was also PI of a number of DoD-sponsored R\&D programs, including: "Development of Fine-Grained, Ductile Tungsten for Armor/AntiArmor Applications" and "Superplasticity in Fine-Grained Ceramic Composites", and "High Strain Rate Superplasticity", sponsored by Army Research Office; "Development of Refractory Metal Beryllides for Aerospace Application" sponsored by Air Force Office of Scientific Research; "Microlaminates", sponsored by Naval Air Development Center; "Fundamental Study of the Rapidly-Solidified Al-Be-Li Alloys", sponsored by Office of Naval Research; "Development of Advanced Metallics for Structural Aerospace Applications", sponsored by DARPA/Office of Naval Research; and "Beryllium Mirror Fabrication by Vapor Deposition", sponsored by Army System Defense Command. In addition to research and contractual works, Dr. Nieh provided strong technical supports to the product divisions in Lockheed, in the areas of 
failure analysis of $\mathrm{Al}$ and $\mathrm{Ti}$ alloys, steels, refractory metals, and ceramics, joining and welding of structural metals, and low observables (i.e. stealth technology). He has a broad interest in different materials, .as reflected in his publications. However, his main research is to develop and promote advanced materials, these include the synthesis, processing, characterization, and applications, of these materials.

Dr. Nieh received his BS degree in Physics from Cheng-Kung University, Taiwan, in 1973, and a MS degree also in Physics from the University of Washington, Seattle, in 1976. He obtained his Ph.D. degree in Materials Science and Engineering from Stanford University in 1980, and soon began working at Lockheed Missiles and Space Company. In August 1992, he joined the Chemistry and Materials Science Directorate, Lawrence Livermore National Laboratory. He was Consulting Professor in Department of Materials Science and Engineering, Stanford University, from 1988 to 1992, teaching a graduate course on "Strength and Microstructure". He was President, Chinese American Materials Association, 1987-1989. In 1992, he was elected Fellow of ASM International. $\mathrm{He}$ is currently Member of the Editorial Board for two International Journals -International Materials Review and Intermetallic. $\mathrm{He}$ is also a board member of the International Advisory Board on Superplasticity. He is a member of TMS, MRS, ASM International, and American Ceramic Society.

Dr. Nieh has authored or co-authored over 260 technical papers in a wide range of materials and materials-related fields, including composites, superplasticity, aluminum alloys, intermetallics, refractory metals, thin films, nanostructured materials, and amorphous alloys. He also wrote a text book "Superplasticity in Metals and Ceramics" published by Cambridge University Press in 1997. Some of the recent publications relevant to this proposed research are:

T.G. Nieh and J. Wadsworth, 'Fine-Structure Superplastic Intermetallics,' International Materials Review, 44(2), 59-75 (1999).

T.G. Nieh, T.W. Barbee, and J. Wadsworth, 'Tensile Properties of a Free-Standing Cu/Zr Nanolaminate,' Scr. Mater. , 41(9), 929-935 (1999).

S. Suresh, T.G. Nieh, and B.W. Choi, 'Nano-Indentation of Copper Thin Films on Silicon Substrates,' Scr. Mater. , 41(9), 951-957 (1999).

J.G. Wang, B.W. Choi, T.G. Neh, and C.T. Liu, 'Crystallization and Nanoindentation Behavior of a Bulk $\mathrm{Zr}-\mathrm{Al}-\mathrm{Ti}-\mathrm{Cu}-\mathrm{Ni}$ Amorphous Alloy,' J. Mater. Res., 15(3), 798-807 (2000). 
Mikrajuddin, F.G. Shi, T.G. Nieh, and K. Okuyama, 'Metalto-Semiconductor Transition in Nanocrystals: Size and Temperature Dependence,' Microelectronics J. 31(5), 343-351 (2000).

J. G. Wang, B. W. Choi, T. G. Nieh, and C.T. Liu, 'Nano-Scratch Behavior of a Zr-Based Bulk Amorphous Alloy,' J. Mater. Res., 15(4), 913-922 (2000).

P. Asoka-Kumar, J. Hartley, R. Howell, P.A. Steme, and T.G. Nieh, 'Chemical Ordering

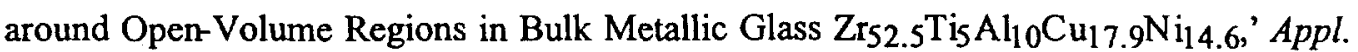
Phys. Lett. , 77(13), 1973-1975 (2000).

T.G. Nieh, J. Wadsworth, C.T. Liu, G.E. Ice, K.-S. Chung, 'Extended Plasticity in the Supercooled Liquid Region of Bulk Metallic Glasses,' Mater. Trans. JIM, 42(4), 613-618 (2001).

S. Namilae, C. Shet, N. Chandra, and T.G. Nieh, 'Atomistic Simulation of the Effect of Trace Elements on Grain Boundary of Aluminum,' Mater. Sci. Forum, 357-359, 387-392 (2001). 


\section{MARÍA JOSÉ CATURLA}

\section{Education}

? PhD., Physics, University of Valencia, Spain, Dept. of Theoretical Physics, June 1996

Title: Ion implantation in Si: amorphization and recrystallization processes.

? M.S., Physics, University of Alicante, Alicante, Spain, April 1993

? B.S., Physics, University of Valencia, Valencia, Spain, July 1991

\section{Experience}

- Flexible Term research staff member at Lawrence Livermore National Laboratory, since July 1, 1999

? Post-Dr. research staff member at Lawrence Livermore Nat, Lab., July 15, 1996 July 1,1999

Research topics: Computer simulation using classical molecular dynamics and Monte Carlo simulators.

Projects:

- Modeling of deformation of nanocrystalline materials

- Modeling damage of silica glass

- multi-scale modeling of radiation damage production and defect evolution in heavy metals.

4. modeling of Boron diffusion in Silicon combining results from ab initio calculations, classical Molecular Dynamics, kinetic Monte Carlo and continuum models

? Teaching assistant at the Dept. of Applied Physics from the Univ.of Alicante, Spain, April-July 1996

- Participating Guest, May 1993 to April 1996 Lawrence Livermore National Laboratory, CA.

Projects:

1. Deformation of nanocrystalline materials

2. Damage of glasses

3. Ion and electron beam induced epitaxial crystallization (IBIEC L\& EBIEC) in Si.

4. Ion implantation of $\mathrm{B}$ and $\mathrm{As}$ in Si with energies of a few keV.

5. Recrystallization kinetics of amorphous pockets in crystalline material.

- Teaching assistant at the Centro de Educación "Los Molinos", Spain Astronomy for students between 6 and 18 years old.

\section{Computational Skills}

Experience in Parallel Computing on Massive Parallel Platforms (CRAY T3D \& T3E, ASCI Blue) using PVM and MPI.

Programming Languages: Fortran, La TeX typesetting, HTML for WWW, basic knowledge of C.

Computer Operating Systems: UNIX, MACINTOSH, MS-DOS

Platforms: CRAY C90, DEC workstation, SGI, MACINTOSH, PC

Graphics programs: AVS, Renderman 


\section{Additional Experience}

Editor and part of the local organizing committee of the $2^{\text {nd }}$ Conference on computer simulation of radiation effects in solids, Santa Barbara, California, 1994

\section{Publications}

Dr, Caturla has published over 30 papers. The most recent ten publications are:

A. Caro, H. Van Swygenhoven, P. Derlet, D. Farkas, M. J. Caturla, T. Diaz de la Rubia, Atomistic Studies of Plasticity of Nanophase Metals,

Mater. Res. Soc. Symp. Proc., Boston, submitted

M.-J. Caturla, A. Kubota, J. S. Stölken, M. D. Feit

Densification of fused silica due to shock waves and its implications to 3? laser damage Optics Express, 8 (2001)

M.-J. Caturla, Tomas Diaz de la Rubia, and Maximo Victoria, K. Corzine, M. James, G. A. Greene

Multiscale modeling of radiation damage: applications to damage production by GeV proton irradiation of $\mathrm{Cu}$ and $W$, and pulsed irradiation effects in $\mathrm{Cu}$ and $\mathrm{Fe}$

Jour. Nucl. Mater. 296 (2001) 90

1. D. Wirth, A. J. Schwartz, M. J. Fluss, M. J. Caturla, M. A. Wall, W. G. Wolfer, Fundamental studies of plutonium aging

Mat. Res. Soc. Bulletin (2001)

T. Diaz de la Rubia, H. M. Zbib, T. Q. Khraishi, B. D. Wirth, M. Victoria, M.-J. Caturla Plastic flow localization in irradiated materials: a multiscale modeling approach Nature 408, (2000) 871

T. J. Lenosky, B. Sadigh, S. K. Theiss, M.-J. Caturla, T. Diaz de la Rubia Energetics of Boron-Interstitial Clusters in crystalline silicon Appl. Phys. Lett. 77, (2000) 1834

E. Alonso, M.-J. Caturla, T. Diaz de la Rubia, J. Marián, M. Perlado, R. E. Stoller Flux effects on defect production and damage accumulation in $\mathrm{Cu}$ and Fe exposed to IFE like conditions

Jour. Nuclear Mater 283-287 (2000), 768-772

S. K. Theiss, M.-J. Caturla, M. D. Johnson, J. Zhu, T. J. Lenosky, B. Sadigh, T. Diaz de la Rubia

Atomic scale models of ion implantation and dopant diffusion in silicon

Thin Solid films 365, (2000), 219

S. K. Theiss, M.-J. Caturla, T. J. Lenosky, B. Sadigh, T. Diaz de la Rubia, M. Giles, M.

A. Foad 
First-Principles-Based predictive simulations of $B$ diffusion and activation in ion implanted $\mathrm{Si}$

(International Conference on Simulation Semiconductor Processes and Devices, Seattle, Sept. 2000). IEEE (2000), p. 18-22

M.-J. Caturla, N. Soneda, E. Alonso, B. D. Wirth, T. Diaz de la Rubia, M. Perlado Comparative study of radiation damage accumulation in $\mathrm{Cu}$ and $\mathrm{Fe}$

J. of Nucl. Mat., 2000, V276:13-21 